\title{
Correction to: Fishbone Diagram: Application to Identify the Root Causes of Student-Staff Problems in Technical Education
}

\author{
Dnyandeo Dattatraya Shinde ${ }^{1} \cdot$ Shwetambari Ahirrao $^{2} \cdot$ Ramjee Prasad $^{3}$
}

Published online: 19 February 2018

(C) Springer Science+Business Media, LLC, part of Springer Nature 2018

\section{Correction to: Wireless Pers Commun https://doi.org/10.1007/s11277-018-5344-y}

There were spelling errors in the second author's name in the initial online publication. The original article has been corrected.

The original article can be found online at https://doi.org/10.1007/s11277-018-5344-y.

Dnyandeo Dattatraya Shinde

dnyandeo.shinde@sandipuniversity.edu.in

Shwetambari Ahirrao

shweta.ahirrao23@gmail.com

Ramjee Prasad

ramjee@btech.au.dk

1 Department of Mechanical Engineering, School of Engineering and Technology, Sandip University, Mahiravani, Nashik, Maharashtra, India

2 Department of Mechanical Engineering, Sandip Foundations, SIEM, Mahiravani, Trimbak Road, Nashik 422013, India

3 Department of Business Development and Technology, Aarhus University, Herning, Denmark 